\title{
Shooting Ball Accuracy with U16 Soccer Players after Preparation Period
}

\author{
Jovan Gardasevic ${ }^{1}$ and Dusko Bjelica ${ }^{1}$ \\ ${ }^{1}$ University of Montenegro, Faculty for Sport and Physical Education, Niksic, Montenegro
}

\begin{abstract}
The main aim of the research was to identify a level of quantitative changes of the shooting ball accuracy with U16 soccer players under the influence of the programmed soccer training of six weeks a summer preparation period. The training programme covered 44 training units. The research was made on a sample of 120 soccer players. For the assessment of shooting ball accuracy the three tests were used: Straight foot accuracy in the vertical target, Elevation foot accuracy in the vertical target and Elevation head accuracy in the vertical target. In the area of comparative statistics, used t-test for big paired samples. Based on the numerical values of the t-test it can be concluded that there are statistically significant differences in all three variables to estimate the shooting ball accuracy. In this research the authors were guided by the fact that this kind of training program in preparation period, where dominates the situational model training is very effective in terms of raising the shooting ball accuracy with U16 soccer players, because the model that is used in this training period abounds in exercises in which dominates the shooting ball accuracy, in straight and elevation line. The obtained results can be directed towards innovation plans and programs in the preparation period, and the adaptation of the same needs of the respective population.
\end{abstract}

Key words: soccer, soccer players, preparation period, shooting ball accuracy

\section{Introduction}

Soccer is the most popular sport in the world, with close to 270 million participants (Akbari, Sahebozamani, Daneshjoo, \& Amiri-Khorasani, 2018). Soccer is a sport that is characterized by numerous and varied complex dynamic kinesiology activities that are characterized by a large number of cyclic and acyclic movements (Gardasevic, Bjelica, \& Vasiljevic, 2017; Sermaxhaj, Popovic, Bjelica, Gardasevic, \& Arifi, 2017). Soccer consists of various types of movements and actions like tackling, jumping, sprinting and kicking (Reilly, Williams, Nevill, \& Franks, 2000; Amiri-Khorasani, Osman, \& Yusof, 2009). The high specificity of loading, decision making under pressure of opponents (Hulka, \& Weisser, 2017) in all four moments of play, possession of the ball, the opponent's possession of it, the transformation after winning the ball and the transformation after losing the ball depends on the ability of players to perform certain movements of varying intensity, in different directions and the different sections of the field (Gardasevic, Bjelica, \& Corluka, 2018a; Gardasevic, Bjelica, \&
Corluka, 2018b). They must have developed basic and specific motor abilities (Gardasevic, \& Vasiljevic, 2017). Level of adaptations and time to reach at degree of adaptation according to training objectives are determining type of training which coaches may choose (Amani, Sadeghi, \& Afsharnezhad, 2018). One of the specific motor skills, which should be at a high level, is a shooting ball accuracy.

The shooting ball accuracy is considered as the very important ability of the soccer player. A good soccer player is the one who is able to perform complex situational-motor actions coordinated in a certain space and in time period as short as possible and with good shooting ball accuracy (Corluka et al., 2018).

The main objective of this study was to determine the level of quantitative changes of the shooting ball accuracy with U16 soccer players, under the influence of a programmed soccer training which included one preparatory period of forty-two days.

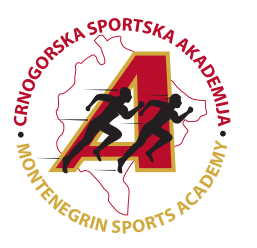

Correspondence:

J. Gardasevic

University of Montenegro, Faculty for Sport and Physical Education, Niksic, Montenegro

E-mail: jovan@ucg.ac.me 


\section{Methods}

This was a longitudinal study with an aim that in the two time-varying points determine quantitative changes of the shooting ball accuracy in soccer players ( 15 years \pm 6 months) under the influence of programmed training process, which included a summer preparation period for the competition season in a unique cadet league of Montenegro and the cadet league middle region of Montenegro. The training program lasted 42 days and was carried out on the auxiliary soccer field of FC Sutjeska-Niksic. The training program included 44 trainer units, within which 8 friendly matches were played.

For data processing only the results of those respondents who have undergone a complete program of work and who have joined the initial and final measurement are taken. This study included a sample of 120 young cadet soccer players of 4 teams, all from Niksic. Parents of all participants signed a consent form, which was in accordance with the Helsinki Declaration. Before programmed work all respondents had passed medical check-ups to make sure they could access the training process. When selecting the instruments (tests) it was taken into account that they meet the basic metric characteristics, which means the appropriate age and objective material and spatial conditions. For the assessment of the shooting ball accuracy, the following tests were used: 1 . Straight foot accuracy in the vertical target; 2 . Elevation foot accuracy in the vertical target; 3 . Elevation head accuracy in the vertical target.

Straight foot accuracy in the vertical target is performed in an open or closed space of minimum dimensions of $30 \times 5$ meters. The participant stands with a ball 25 meters from the goal. He leads the ball 5 meters with two touches and shoots it on goal from 20 meters away from the goal. The participant has 10 knocks on the goal. Points are: hit the central goal (the goal is $1.5 \mathrm{~m}$ wide) $=3$ points; hit the goal from the side (the goals are $1 \mathrm{~m}$ wide $)=2$ points; hit above and beside goal $=1$ point

Elevation foot accuracy in the vertical target is performed on the football field. The participant stands with a ball 30 meters from the goal. He leads the ball 5 meters with two touches and shoots it on goal from 20 meters away from the goal. The participant has 10 knocks on the goal. Points are: hit the goal that the ball does not reach the ground in its path=3 points; hit in the goal frame that the ball does not reach the ground in its path $=2$ points; hit above and beside goal=1 point; if the ball on its way reaches the ground before entering the goal=1 point.

Elevation head accuracy in the vertical target is performed in an open or closed space of minimum dimensions of $15 \times 5$ meters. The participant stands with a 15 meters from the goal. He leads the ball 5 meters his head with two touches and shoots it on goal his head from 10 meters away from the goal. The participant has 10 knocks on the goal. Points are: hit the goal that the ball does not reach the ground in its path $=5$ points; hit the goal that the ball has one touch the ground in its path $=3$ points; hit in the goal frame and missed the goal=1 point; hit above and beside goal=1 point; if the ball on its way reaches the ground before entering the goal=1 point.

Considering that these are cadet age players (15-years \pm 6 months), in a sensitive period of psychophysical development, program is tailored specifically to their age, taking into account the time spent in the previous training process. Time structure of the training ranged from 60 to 120 minutes, depending on the goals and objectives of the training unit and it was divided into 3 phases: 1 . Introductory-preparatory part (25-30\% of the duration of training); 2 . The main part $(60-65 \%$ of the duration of the training); 3 . The final part (up to $10 \%$ of the duration of training)

In the introductory-preparatory part of the training the emphasis was on raising the operating temperature in children. As a tool, various elementary games with a ball were used that enabled work on the elementary basics of technique and tactics, also the various polygons with exercises the shooting ball accuracy were used. A variety of games and exercises to increase joint mobility and strengthen muscles also applied at this stage.

At the first stage of the main part of the training the intensity is slightly increased compared to the warm-up phase and the training program was implemented through a variety of ball games. With a game method, the respondents were taught and practiced soccer skills through a large number of repetitions. At the second stage of the main part of the training the players mostly had a free game on two goals that allowed them creative activities and highlight of individual, imagination, independent thinking and hard work, applying the elements that teach by the method of the game from the first stage of the main part, and thus strengthening the willing quality. At this stage of the training the intensity was the greatest. At the final part of the training the task was lowering the physiological curve to an optimum level, and low-intensity activities were used: stretching and relaxation exercises, competitive game of penalty kicks, free kicks.

Data obtained from the survey were analysed using descriptive and comparative statistics. In the area of descriptive statistics for each variable both in the initial and the final state central and dispersion parameters were processed as well as measures of asymmetry and flatness. The hypothesis of normal distribution of results was tested on the basis of Kolmogorov and Smirnov test. In the area of comparative statistics, to determine differences in the variables used to estimate the shooting ball accuracy at the start (initial state) and at the end (final state) of the training program in the preparation period, we used the discriminative parametric procedure Student's t-test for large dependent samples.

\section{Results}

In Tables 1 and 2 are shown the basic descriptive statistical parameters of variables for estimations of the shooting ball accuracy in the initial and final measurement, where the values of central and dispersion tendency were calculated: arithmetic mean (Mean), standard deviation (Std.D.), standard error of arithmetic mean (Std.E.), the coefficient of variation (CV\%), minimum (Min) and maximum (Max) values, the range of results (Range), the curvature coefficient Skewness (Skew) and elongation Kurtosis (Kurt), as well as the values of Kolmogorov and Smirnov test (K-S).

First the central and dispersive parameters of variables for assessing the shooting ball accuracy in the initial state were analysed (Table 1). 
Table 1. Central and dispersive parameters of variables for assessing the shooting ball accuracy in the initial state

\begin{tabular}{cccccccccccc}
\hline No & Variable & Mean & Std.D. & Std.E. & CV\% & Min & Max & Range & Skew & Kurt & K-S \\
\hline 1 & SFAVTI & 19.76 & 3.24 & 0.30 & 16.38 & 10 & 26 & 16 & -0.50 & 0.04 & 0.05 \\
2 & EFAVTI & 32.33 & 3.35 & 0.31 & 10.37 & 26 & 38 & 12 & -0.18 & -0.78 & $0.00^{*}$ \\
3 & EHAVTI & 19.54 & 4.11 & 0.37 & 21.01 & 9 & 27 & 18 & -0.64 & 0.25 & 0.26 \\
\hline
\end{tabular}

Legend: SFAVTI-straight foot accuracy in the vertical target-initial state; EFAVTI-elevation foot accuracy in the vertical target-initial state;

EHAVTI-elevation head accuracy in the vertical target-initial state

By analysing the central and dispersion parameters of variables for assessing the shooting ball accuracy in the initial state-values of Kolmogorov and Smirnov test shows that the results in the variable EFAVTI-elevation foot accuracy in the vertical target, have statistically significantly deviation from the normal distribution. For the other two variables for asse- ssing the shooting ball accuracy - it can be seen that the range of results is quite large.

Central and dispersive parameters of variables for estimation of the shooting ball accuracy in the final measurement showed the following values (Table 2).

Table 2. Central and dispersive parameters of variables for assessing the shooting ball accuracy in the final state

\begin{tabular}{cccccccccccc}
\hline No & Variable & Mean & Std.D. & Std.E. & CV\% & Min & Max & Range & Skew & Kurt & K-S \\
\hline 1 & SFAVTF & 23.30 & 2.52 & 0.23 & 10.81 & 15 & 27 & 12 & -0.67 & -0.07 & $0.00^{*}$ \\
2 & EFAVTF & 41.40 & 3.38 & 0.31 & 8.16 & 36 & 48 & 12 & 0.14 & -0.91 & 0.02 \\
3 & EHAVTF & 27.45 & 4.42 & 0.40 & 16.08 & 15 & 36 & 21 & -0.56 & 0.54 & 0.20 \\
\hline
\end{tabular}

Legend: SFAVTF-straight foot accuracy in the vertical target-final state; EFAVTF-elevation foot accuracy in the vertical target-final state; EHAVTF-elevation head accuracy in the vertical target-final state

By analysing the central and dispersive parameters of variables for estimation of the shooting ball accuracy in the final stage-it may be noted that the values of arithmetic means are in all three variables at a higher level than in the initial state. The values of Kolmogorov and Smirnov test shows that the results in the variable SFAVTF-straight foot accuracy in the vertical target, have statistically significantly deviation from the normal distribution. These results show how that the shooting ball accuracy is complicated for U16 soccer players.
To determine the statistical significance of differences in arithmetic means (partial quantitative changes) of variables for estimation of the shooting ball accuracy, the t-test was applied to for large dependent samples. The values of t-test were on the level of significance (Sig.) from $0.01(\mathrm{p} \leq 0.01)$ in all the variables for the evaluation of the shooting ball accuracy. The differences of arithmetic means of the initial and the final measurement of variables for evaluating the shooting ball accuracy are shown in Table 3.

Table 3. The values of t-test between the arithmetic means of the initial and the final measurement of variables for evaluating shooting ball accuracy

\begin{tabular}{cccccccc}
\hline & Variable & Mean & Std.D. & Std.E. & Correlation & t-test & Sig. \\
\hline \multirow{2}{*}{ Pair 1 } & SFAVTFI & 19.76 & 3.24 & 0.30 & \multirow{2}{*}{0.85} & -22.37 & 0.00 \\
& SFAVTFF & 23.30 & 2.52 & 0.23 & & & \\
\multirow{2}{*}{ Pair 2 } & EFAVTI & 32.33 & 3.35 & 0.31 & & \\
& EFAVTF & 41.40 & 3.38 & 0.31 & & -66.75 & 0.00 \\
\multirow{2}{*}{ Pair 3 } & EHAVTI & 19.54 & 4.11 & 0.37 & \multirow{2}{*}{0.86} & -38.26 & 0.00 \\
& EHAVTF & 27.45 & 4.42 & 0.40 & & & \\
\hline
\end{tabular}

Based on the results gained, it can be noted that there are statistically significant differences in all variables for estimation of the shooting ball accuracy, and therefore can be said that there was statistically significant positive partial effects of the training program in the preparation period, and the t-test values were significant at the reliability level $p<0.01$ for all variables for estimation of the shooting ball accuracy.

\section{Discussion}

The aim of this study was to, based on the training work program of forty-two (42) days, determine the level of transformation of the shooting ball accuracy with U16 soccer players, under the influence of a scheduled soccer training that included one preparatory period. This study included a sample of 120 young cadet soccer players of 4 teams, all from Niksic, competing in a unique Montenegrin cadet league and in the middle region league of Montenegro. On the basis of the obtained parameters it can be concluded that the statistically significant partial quantitative effects (changes) in all the variables for estimation of the shooting ball accuracy obtained as a result of the training program applied in the preparation period. The method of work that has been applied in this training program abounds with exercises dominated by movements with ball in various directions, players are often found in unexpected situations, so that the positive transformations are not unexpected (Gardasevic, Bjelica, \& Vasiljevic, 2016).

Based on the results of t-test for large dependent samples, with the variables for estimation of the shooting ball accuracy the statistically significant differences were determined in all pairs of variables between the initial and final states, at the level of statistical significance (significance), $p<0.01$. It can be concluded that the training program of work in preparation period has led to the positive transformation in all variables that were estimating, by the structure of a hypothetical setting of the models, the shooting ball accuracy. In this research, the authors were guided by the fact that such a training program of work in preparation period is a very efficient way of working in terms of raising the level of the shooting ball accuracy with 
cadet soccer players. The authors conclude that the summer period of 42 days, at cadet soccer players, with such training work program, is optimal for lifting the shooting ball accuracy to the level required for the competition. The gained results can be directed towards innovation of plans and programs of work in the preparation period, and adjusting the same to the needs of the talented players, because European top-level soccer clubs are continually looking for the most talented players.

\section{Acknowledgements}

There are no acknowledgements.

\section{Conflict of Interest}

The authors declare that there are no conflicts of interest.

Received: 25 September 2018 | Accepted: 30 October 2018| Published: 01 February 2019

\section{References}

Akbari, H., Sahebozamani, M., Daneshjoo, A., \& Amiri-Khorasani, M. (2018) Effect of the FIFA 11+ programme on vertical jump performance in elite male youth soccer players. Montenegrin Journal of Sports Science and Medicine, 7(2), 17-22. doi: 10.26773/mjssm.180903

Amani, A.R., Sadeghi, H., \& Afsharnezhad, T. (2018). Interval training with blood flow restriction on aerobic performance among young soccer players at transition phase. Montenegrin Journal of Sports Science and Medicine, 7(2), 5-10. doi: 10.26773/mjssm.180901

Amiri-Khorasani, M., Osman, N.A.A., \& Yusof, A. (2009). Biomechanical responds of instep kick between different positions in professional socce players. Journal of Human Kinetics, 22(1), 21-27. doi: 10.2478/v10078009-0019-0
Corluka, M., Bjelica, D., Vasiljevic, I., Bubanja, M., Georgiev, G., \& Zeljko, I. (2018). Differences in the morphological characteristics and body composition of football players of hsc zrinjski mostar and fc siroki brijeg in bosnia and herzegovina. Sport Mont, 16(2), 77-81. doi: 10.26773/ smj.180614

Gardasevic, J., Bjelica, D., \& Corluka, M. (2018a). The impact of the preparation period on endurance at football players U16. Sport Mont, 16(1), 2124. doi: $10.26773 /$ smj.180204

Gardasevic, J., Bjelica, D., \& Corluka, M. (2018b). The impact of the preparation period on endurance at football players U16. Sport Mont, 16(1), 2124. doi: $10.26773 / \mathrm{smj}$.180204

Gardasevic, J., \& Vasiljevic, I. (2017). The effects of the training in the preparation period on the coordination transformation with football players U16. Kinesiologia Slovenica, 23(3), 12-17.

Gardasevic, J., Bjelica, D., \& Vasiljevic, I. (2017). The strength of kicking the ball after preparation period with U15 football players. Sport Mont, 15(2), 3942.

Gardasevic, J., Bjelica, D., \& Vasiljevic, I. (2016). Six-Week Preparation Period and its Effects on Transformation Movement Speed with Football Players Under 16. Sport Mont, 14(1), 13-16. udc 796.13:796.332-053.6

Hulka, K., \& Weisser, R. (2017). The Influence of the Number of Players on Workload during Small-Sided Games among Elite Futsal Players. Montenegrin Journal of Sports Science and Medicine, 6(1), 45-48.

Reilly, T., Williams, A.M., Nevill, A., \& Franks, A. (2000). A multidisciplinary approach to talent identification in soccer. Journal of sports sciences, 18(9), 695-702. doi: 10.1080/02640410050120078

Sermaxhaj, S., Popovic, S., Bjelica, D., Gardasevic, J., \& Arifi, F. (2017). Effect of recuperation with static stretching in isokinetic force of young footbal players. Journal of Physical Education and Sport, 17(3), 1948-1953. doi: 10.7752/jpes.2017.03191 